\title{
Vital and non-vital formation of the root end: apexogenesis and apexification
}

\section{Editorial}

\section{Apexogenesis}

It is a vital pulp therapy procedure performed to encourage continued development and formation of the root end. The important role that stem cells have in root formation is related to the biological activity of Hertwig's epithelial root sheath (HERS). HERS is implicated in root formation and shape. It has the capacity to self-replicate and differentiate into specialized tissue type. Both odontoblasts and Höhl cells are located in the outer layers of the pulp. They contribute to the pulp-dentine complex and secrete dentine. Following an initial formation and eruption, secondary dentinogenesis is occurring, which is not suppose to stop but occurs at a slower rate throughout the whole lifetime. As the root and pulp develop, the root end located in the apical zone of the pulp is referred to the apical papilla. Once destroyed, the HERS interrupts the normal root development without further differentiation of pulp stem cells into odontoblasts. Hence, apexogenesis is a continuous process involving mostly root(s) lengthening.

\section{Apexification}

It contributes to induce a calcified barrier in a root with an open apex with a non-vital pulp. It implies also a continued apical development of an incompletely formed root. Along this line, apexification is a method of inducing apical closure of an incompletely formed non-vital permanent tooth. The necrotic radicular tissue is removed at short distance from the root end. Since the pionner investigation using $\mathrm{Ca}(\mathrm{OH})_{2},{ }^{1}$ mineral trioxyde aggregate (MTA) was also adopted as a medicament for endodontics apexification. MTA has excellent biocompatibility as well as sealing, osteogenesis, and cementogenesis abilities. ${ }^{2}$ The apical region of an immature permanent tooth share these properties with the dental pulp, apical papilla and periodontal tissues, properties that are developed throughout a series of ectomesenchymal interactions. Apexification enables a calcified barrier to be formed at the root apex by placing the biocompatible material against the periapical tissues via the root canal. It involves the closure of a permanent tooth at least 3 years after eruption. Placing a biocompatible agent such as $\mathrm{Ca}(\mathrm{OH})_{2}$ or MTA in the canals for two to four weeks, allows the disinfected canal space to display lengthening. Root end closure is what is referred to apexification.

The development of the apical tissues implies dental stem cells and their possible clinical involvement in closing the open root apex. Dental pulp stem cells (DPSCs), stem cells from human exfoliated teeth (SHED), stem cells from apical papilla (SCAP), as well as periodontal ligament stem cells (PDSCs) and dental follicle progenitor cells are implicated in dental tissues regeneration and apexification. The completion of root development and closure of the root apex of permanent tooth constitue irreversible injury to the immature non-vital dental pulp. Tooth maturation is stopped at this stage. An immature permanent tooth remains with an open root apex, with thin and weak root walls, and a discontinuous periodontal ligament. This event plays a role in the continued root development (apexogenesis), whereas apexification is implicated in the apical closure in the irreversibly damaged pulp. ${ }^{3}$
Volume 10 Issue 2 - 2019

\author{
Michel Goldberg \\ Department of Oral Biology, Faculty of Fundamental and \\ Biomedical Sciences, Paris Descartes University, France
}

Correspondence: Michel Goldberg, Professor Emeritus, Department of Oral Biology, Paris Descartes University, Faculty of Fundamental and Biomedical Sciences \& INSERMUMR-S I I 24. Stem cells, signalization and prions. 45 rue des saints pères, 75006, Paris, France, Tel 33162676709, Emailmgoldod@gmail.com

Received: March 05, 2019| Published: March 14, 2019

Immunohistochemistry and gene profile analysis have identified perivascular cell markers that include CD146/MUC18, 3G5, CD-44, VCAM-1, alkaline phosphatas, $\alpha$-smooth muscle actin in differing proportions on STRO-1 positive cells from dental tissues. Fibroblast growth factor, and members of the transforming growth factor beta (TGF $\beta$ ) superfamily include also a series of bone morphogenic proteins (BMPs), platelet-derived growth factor (PDGF) and insulin-like growth factor (IGF). They have specific and sometimes overlapping functions on stem cell control. BMPs appear to be key regulators of stem cells proliferation and differentiation into pluripotent cell lines. At a molecular level, two transcription factors Notch and Wnt signalling pathways play a critical role in the development and control of stem cell fate. Both are negatively inhibiting odontoblast differentiation. The cell lines need to be grown and expanded before being implanted into the root canal. The implanted cells also need to adhere to the disinfected root canal walls. This dictate a change in the way clinicians currently debride and disinfect root canals. Where an open root apex exists, a similar scaffold design adjacent to a vascular supply may assist apexification by thickening and closing the apical portion of the root with hard tissue.

There are no published reports involving the use of genetically manipulated cells for apexogenesis or apexification procedures. The phenotype of cells re-populating the open root apex has to be selected by environmental factors. We are still at an early stages in identifying novel genes and finding appropriate vectors for controlled cell-specific safe delivery. ${ }^{3,4}$

\section{Acknowledgments}

None.

\section{Conflicts of interest}

The author declares that there is no conflict of interest.

\section{References}

1. Hermann BW. Calcium hydroxide als mittel zum behandel und fullen von zahnwurzelkanalen. Dissertation. Germany: University of Wuzburg, Med Diss V; 1920

2. Torabinejad M, Watson TF, Pitt Ford TR. Sealing ability of mineral trioxide aggregate when used as a root end filling material. $J$ Endod. 1993;19(12):591-599. 
3. Friedlander LT, Cullinan MP, Love RM. Dental stem cells and their potential role in apexogenesis and apexification. Internat Endod J. 2009;42(11):955-962.
4. Sonoyama W, Liu Y, Yamaza T, et al. Characterization of the apical papilla and its residing stem cells from human immature permanent teeth: a pilot study. J Endod. 2008;34(2):166-171. 